\title{
Noninvasive Ventilation Intolerance: Characteristics, Predictors, and Outcomes
}

\author{
Jinhua Liu RN, Jun Duan MD, Linfu Bai MD, and Lintong Zhou MD
}

\begin{abstract}
BACKGROUND: Noninvasive ventilation (NIV) intolerance is one reason for NIV failure. However, the characteristics, predictors, and outcomes of NIV intolerance are unclear. METHODS: A prospective observational study was performed in the respiratory intensive care unit of a teaching hospital. Subjects with acute respiratory failure who used NIV were enrolled. Initially, continuous use of NIV was encouraged. However, if the subject could not tolerate NIV, it was used intermittently. NIV intolerance was defined as termination of NIV due to subject refusal to receive it because of discomfort, even after intermittent use was attempted. RESULTS: A total of 961 subjects were enrolled in the study. Of these, 50 subjects (5.2\%) experienced NIV intolerance after a median $2.4 \mathrm{~h}$ of NIV support. Age $(\mathrm{OR}=0.98,95 \%$ CI $0.963-0.996)$ and heart rate $(\mathrm{OR}=1.02,95 \% \mathrm{CI} 1.006-1.030)$ measured before NIV were 2 independent risk factors of NIV intolerance. After 1-2 h of NIV, independent risk factors of NIV intolerance were heart rate $(\mathrm{OR}=1.03,95 \% \mathrm{CI} 1.016-1.044)$ and breathing frequency $(\mathrm{OR}=1.06,95 \%$ CI 1.027-1.099). Intolerant subjects had no improvement in mean arterial pressure, heart rate, or breathing frequency after the NIV intervention. Moreover, intolerant subjects had a higher intubation rate (44.0\% vs $25.8 \%, P=.008)$ and higher mortality $(34.0 \%$ vs $22.4 \%, P=.08)$. The three most common complaints were that NIV worsened subjects' distress $(46 \%)$, that NIV resulted in dyspnea $(26 \%)$, and that the flow or pressure of NIV was too strong to bear $(16 \%)$. CONCLUSIONS: NIV intolerance worsened subjects' outcomes. Younger subjects with a high heart rate and breathing frequency may be more likely to experience NIV intolerance. Key words: noninvasive ventilation; intolerance; predictor; intubation. [Respir Care 2016;61(3):277-284. (C) 2016 Daedalus Enterprises]
\end{abstract}

\section{Introduction}

Noninvasive ventilation (NIV) reduces intubation rates, decreases the incidence of ventilator-associated pneumo-

\footnotetext{
The authors are affiliated with the Department of Respiratory Medicine, First Affiliated Hospital of Chongqing Medical University, Chongqing, China.

This work was supported by the National Key Clinical Specialist Construction Programs of China (2012 No. 649). The authors have disclosed no conflicts of interest.

Correspondence: Jun Duan MD, Department of Respiratory Medicine, First Affiliated Hospital of Chongqing Medical University, Youyi Road 1, Yuzhong District, Chongqing 400016, China. E-mail: duanjun412589@163.com.
}

DOI: $10.4187 /$ respcare. 04220 nia, and shortens ICU stays in patients with acute respiratory failure. ${ }^{1-4}$ However, some patients fail to see an improvement in their acute respiratory failure because of NIV failure, and are intubated. Previous studies have reported that NIV intolerance is one of the causes for intubation, ${ }^{5-11}$ and one of the studies $^{8}$ has shown that poor NIV tolerance is associated with higher intubation rates. According to Antonelli et al, ${ }^{7}$ NIV intolerance accounted for $25 \%$ of all intubations in subjects with ARDS. In another study, also reported by Antonelli et al, ${ }^{12}$ it accounted for $9 \%$ of intubations in subjects with acute hypoxemic respiratory failure. However, these studies only reported the rate of NIV intolerance. The clinical characteristics, outcomes, and association with intubation of NIV intolerance are unclear. Thus, the aim of this study was to report the characteristics, predictors, and outcomes of NIV intolerance in subjects with acute respiratory failure. 


\section{Methods}

From May 2011 to September 2014, we performed a prospective observational study in the respiratory ICU of a teaching hospital. The investigational review board of the First Affiliated Hospital of Chongqing Medical University approved the study. The initiation of NIV in subjects with acute respiratory failure was in line with

See the Related Editorial on Page 393

the following indictors but ultimately was at the discretion of attending physicians. At least one of the following indicators was required for NIV to be initiated: (1) breathing frequency $>25$ breaths/min, (2) $\mathrm{pH}<7.35$, (3) $\mathrm{P}_{\mathrm{aCO}_{2}}$ $>45 \mathrm{~mm} \mathrm{Hg}$, (4) $\mathrm{P}_{\mathrm{aO}_{2}} / \mathrm{F}_{\mathrm{IO}_{2}}<200 \mathrm{~mm} \mathrm{Hg}$, or (5) vigorous activity of accessory respiratory muscles. ${ }^{13}$ Exclusion criteria for NIV were as follows: recent facial or cranial trauma or surgery, facial abnormalities, active upper gastrointestinal bleeding, high risk of aspiration, inability to clear sputum, and agitation. We enrolled all subjects who underwent NIV because of acute respiratory failure. However, patients younger than $18 \mathrm{y}$ old and those with a do-not-intubate order were excluded from the study. Before or during the study, written informed consent was obtained from subjects. If subjects were unable to sign the written informed consent because of functional limitations, the informed consent was signed by their next of kin.

NIV was managed by attending physicians, respiratory therapists, and nurses. An oronasal mask (ZS-MZ-A face mask, Shanghai Zhongshan Medical Technology, Shanghai, China) was used for all subjects. An appropriately sized mask was chosen based on the subject's facial type. A heated humidifier with a thermometer was used for all subjects. A temperature of $<41^{\circ} \mathrm{C}$ was set based on the subject's comfort, tolerance, and adherence. ${ }^{14}$ If humidification was not adequate, intermittent drinks were given. To balance skin breakdown and excessive air leaks, we kept air leaks at $<30 \mathrm{~L} / \mathrm{min}$, and straps were made as tight as comfortably possible. If there were no contraindications, all subjects were positioned at $30-45^{\circ}$ to avoid aspiration.

The initial modes were CPAP or spontaneous/time mode (BiPAP Vision or V60, Philips Respironics, Murrysville, Pennsylvania). For subjects with hypoxemia or heart failure only, the initial mode was set as CPAP. For subjects with hypercapnia or vigorous activity of accessory respiratory muscles, spontaneous/time mode was used. In subjects with hypoxemia or heart failure, expiratory positive airway pressure or CPAP was initially set at $4 \mathrm{~cm} \mathrm{H}_{2} \mathrm{O}$ and increased by $1-2 \mathrm{~cm} \mathrm{H}_{2} \mathrm{O}$ to the subject's maximum tolerance, but this was usually limited to $<15 \mathrm{~cm} \mathrm{H}_{2} \mathrm{O}$. $\mathrm{F}_{\mathrm{IO}_{2}}$ was set to maintain $\mathrm{S}_{\mathrm{pO}_{2}}$ at about $95 \%$. In subjects with

\section{QUICK LOOK}

\section{Current knowledge}

Noninvasive ventilation (NIV) intolerance frequently occurs and is one cause for NIV failure. However, the clinical characteristics, predictors, and outcomes of NIV intolerance are unclear.

\section{What this paper contributes to our knowledge}

Reasons for NIV intolerance varied. Younger subjects with a high heart rate and breathing frequency were more likely to experience NIV intolerance. NIV-intolerant subjects showed no improvement in mean arterial pressure, heart rate, or breathing frequency after $1-2 \mathrm{~h}$ of NIV. Moreover, they were more likely to experience intubation and to experience it earlier.

hypercapnia, expiratory positive airway pressure was initially set at $4 \mathrm{~cm} \mathrm{H}_{2} \mathrm{O}$ and titrated according to the flow curve to ensure that the expiratory flow reached zero before inspiration or to diminish ineffective efforts. Inspiratory positive airway pressure was adjusted by increments of $1-2 \mathrm{~cm} \mathrm{H}_{2} \mathrm{O}$ to obtain a tidal volume of $>6 \mathrm{~mL} / \mathrm{kg}$ every $5-6 \mathrm{~min}$ or to the maximum level tolerated by each subject. ${ }^{13}$

Before beginning NIV, we recorded the age, sex, diagnosis, heart rate, breathing frequency, blood pressure, arterial blood gas results, and APACHE II (Acute Physiology and Chronic Health Evaluation II) score of the subject. After 1-2 $\mathrm{h}$ of NIV, vital signs and ventilator parameters were recorded, and arterial blood gas tests were performed. However, for intolerant subjects who received NIV for $<1$ $\mathrm{h}$, these variables were measured and tests were performed at the termination of NIV.

Initially, continuous use of NIV was encouraged. ${ }^{14,15}$ Once respiratory failure was relieved, NIV was used intermittently, and subjects were eventually totally weaned from it. If subjects felt any discomfort during NIV, physicians, respiratory therapists, or nurses checked the pa-

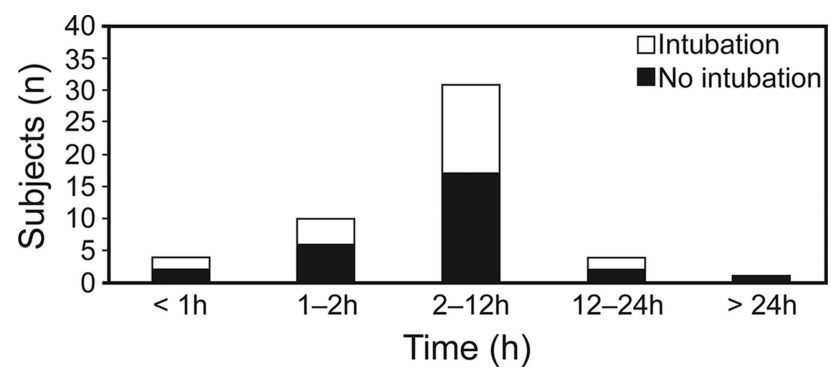

Fig. 1. Time from initiation of noninvasive ventilation to termination in intolerant subjects (median $2.4 \mathrm{~h}$, interquartile range 1.8-4.8 h). 
NIV INTOLERANCE

Table 1. Comparison of Data for Subjects With and Without Noninvasive Ventilation Intolerance

\begin{tabular}{|c|c|c|c|}
\hline Characteristics & NIV Intolerance $(n=50[5.2 \%])$ & NIV Tolerance $(n=911[94.8 \%])$ & $P$ \\
\hline Age, mean \pm SD y & $63.2 \pm 19.1$ & $69.1 \pm 13.8$ & .005 \\
\hline Male/female, $n$ & $37 / 13$ & $659 / 252$ & .87 \\
\hline \multicolumn{4}{|l|}{ Diagnosis, $n(\%)$} \\
\hline COPD exacerbation & $26(52)$ & $522(57.3)$ & .47 \\
\hline Pneumonia & $17(34)$ & $251(27.6)$ & .33 \\
\hline ARDS & $3(6)$ & $43(4.7)$ & .73 \\
\hline Asthma & $0(0)$ & $23(2.5)$ & .63 \\
\hline Pulmonary cancer & $2(4)$ & $21(2.3)$ & .34 \\
\hline Pulmonary embolism & $1(2)$ & $14(1.5)$ & .55 \\
\hline Others & $1(2)$ & $37(4.1)$ & .72 \\
\hline \multicolumn{4}{|l|}{ Data collected at NIV initiation } \\
\hline APACHE II score, mean \pm SD & $18.9 \pm 6.0$ & $17.9 \pm 5.3$ & .15 \\
\hline Mean arterial pressure, mean $\pm \mathrm{SD} \mathrm{mm} \mathrm{Hg}$ & $99 \pm 21$ & $99 \pm 17$ & .94 \\
\hline Heart rate, mean $\pm \mathrm{SD}$ beats/min & $125 \pm 29$ & $113 \pm 24$ & .001 \\
\hline Breathing frequency, mean $\pm \mathrm{SD}$ breaths $/ \mathrm{min}$ & $33 \pm 7$ & $30 \pm 8$ & .02 \\
\hline $\mathrm{pH}$, mean $\pm \mathrm{SD}$ & $7.36 \pm 0.16$ & $7.37 \pm 0.11$ & .29 \\
\hline $\mathrm{P}_{\mathrm{aCO}_{2}}$, mean $\pm \mathrm{SD} \mathrm{mm} \mathrm{Hg}$ & $49 \pm 23$ & $56 \pm 25$ & .049 \\
\hline $\mathrm{P}_{\mathrm{aO}_{2}} / \mathrm{F}_{\mathrm{IO}_{2}}$, mean $\pm \mathrm{SD} \mathrm{mm} \mathrm{Hg}$ & $173 \pm 74$ & $176 \pm 86$ & .76 \\
\hline GCS, mean $\pm \mathrm{SD}$ & $14.8 \pm 0.9$ & $14.6 \pm 1.3$ & .50 \\
\hline $\mathrm{GCS}=15, n(\%)$ & $45(90)$ & $781(86)$ & .53 \\
\hline $\mathrm{GCS}=14, n(\%)$ & $2(4)$ & $73(8)$ & .42 \\
\hline $\mathrm{GCS} \leq 13, n(\%)$ & $3(6)$ & $57(6)$ & $>.99$ \\
\hline \multicolumn{4}{|l|}{ Data collected at $1-2 \mathrm{~h}$ after initiation of NIV* } \\
\hline $\mathrm{S} / \mathrm{T}$ mode, $n(\%)$ & $47(94)$ & 897 (98.5) & .054 \\
\hline CPAP mode, $n(\%)$ & $3(6)$ & $14(1.5)$ & .054 \\
\hline 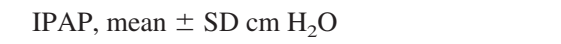 & $10 \pm 4$ & $15 \pm 4$ & $<.001$ \\
\hline $\mathrm{EPAP}$, mean $\pm \mathrm{SD} \mathrm{cm} \mathrm{H} \mathrm{H}_{2} \mathrm{O}$ & $4 \pm 1$ & $5 \pm 2$ & $<.001$ \\
\hline Mean arterial pressure, mean $\pm \mathrm{SD} \mathrm{mm} \mathrm{Hg}$ & $100 \pm 20$ & $91 \pm 14$ & $<.001$ \\
\hline Heart rate, mean $\pm \mathrm{SD}$ beats $/ \mathrm{min}$ & $127 \pm 29$ & $104 \pm 22$ & $<.001$ \\
\hline Breathing frequency, mean $\pm \mathrm{SD}$ breaths $/ \mathrm{min}$ & $34 \pm 11$ & $26 \pm 7$ & $<.001$ \\
\hline $\mathrm{pH}$, mean $\pm \mathrm{SD}$ & $7.39 \pm 0.12$ & $7.39 \pm 0.09$ & .92 \\
\hline $\mathrm{P}_{\mathrm{aCO}_{2}}$, mean $\pm \mathrm{SD} \mathrm{mm} \mathrm{Hg}$ & $47 \pm 20$ & $54 \pm 22$ & $.045^{*}$ \\
\hline $\mathrm{P}_{\mathrm{aO}_{2}} / \mathrm{F}_{\mathrm{IO}_{2}}$, mean $\pm \mathrm{SD} \mathrm{mm} \mathrm{Hg}$ & $204 \pm 101$ & $206 \pm 85$ & .92 \\
\hline \multicolumn{4}{|c|}{$\begin{array}{l}\text { Difference between beginning and } 1-2 \mathrm{~h} \text { after initiation of NIV, } \\
\text { median (IQR)* }\end{array}$} \\
\hline Mean arterial pressure, $\mathrm{mm} \mathrm{Hg}$ & $-2(-10$ to 7$)$ & $6(-1$ to 16$)$ & $<.001$ \\
\hline Heart rate, beats/min & $-1(-11$ to 7$)$ & $8(0-17)$ & $<.001$ \\
\hline Breathing frequency, breaths/min & $0(-5$ to 4$)$ & $4(0-8)$ & $<.001$ \\
\hline $\mathrm{pH}$ & $-0.01(-0.06$ to 0.02$)$ & $-0.01(-0.06$ to 0.03$)$ & .93 \\
\hline $\mathrm{P}_{\mathrm{aCO}_{2}}, \mathrm{~mm} \mathrm{Hg}$ & $1(-4$ to 8$)$ & $1(-4$ to 8$)$ & .77 \\
\hline $\mathrm{P}_{\mathrm{aO}_{2}} / \mathrm{F}_{\mathrm{IO}_{2}}, \mathrm{~mm} \mathrm{Hg}$ & $-30(-85$ to 23$)$ & $-24(-78$ to 23$)$ & .96 \\
\hline $\begin{array}{l}\text { Normally distributed data are reported as mean } \pm \mathrm{SD} \text {, and non- } \\
\text { * In the intolerant group, these data were collected at termination } \\
\text { NIV = noninvasive ventilation } \\
\text { APACHE II = Acute Physiology and Chronic Health Evaluation } \\
\text { GCS = Glasgow coma score } \\
\text { S/T = spontaneous/time } \\
\text { IPAP = inspiratory positive airway pressure } \\
\text { EPAP = expiratory positive airway pressure } \\
\text { IQR = interquartile range }\end{array}$ & $\begin{array}{l}\text { are reported as median (interquartile range). } \\
\text { ho received }<1 \mathrm{~h} \text { of NIV. }\end{array}$ & & \\
\hline
\end{tabular}

rameters, circuit, humidification, air leak, straps, etc to ensure maximum comfort. If subjects still felt uncomfortable, NIV was used intermittently. NIV intolerance was defined as termination of NIV due to the subject's refusal to receive it because of discomfort, even after intermittent use was attempted. ${ }^{16,17}$ We asked subjects why they refused to receive NIV and recorded their answers. After NIV was terminated, intubation was performed on sub- 

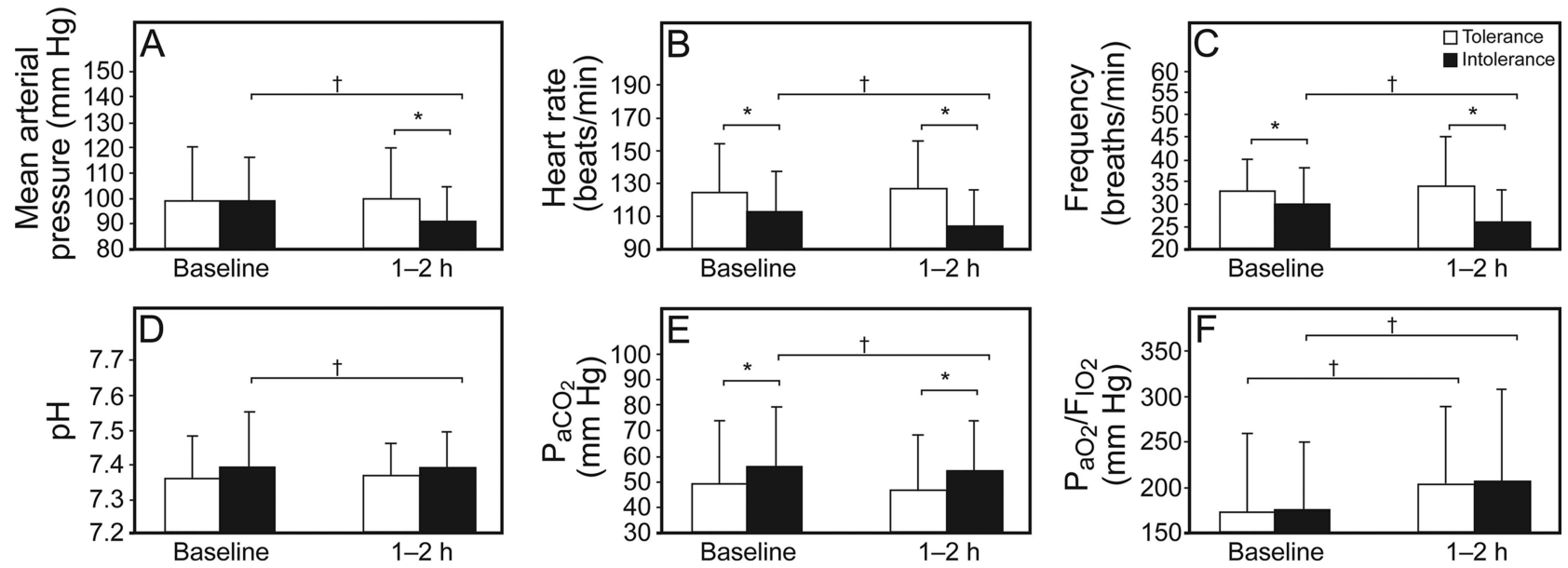

Fig. 2. Comparison of data between and among subjects with and without noninvasive ventilation intolerance. $† P<.05$, baseline versus $1-2 \mathrm{~h}$ of noninvasive ventilation. ${ }^{*} P<.05$, noninvasive ventilation intolerance versus tolerance.

jects who met the criteria for intubation. Subjects who did not meet the criteria for intubation received oxygen therapy.

Intubation was performed based on the following indicators (1 major criterion or at least 2 minor criteria after NIV intervention). ${ }^{13}$ Major criteria were (1) respiratory arrest, (2) loss of consciousness, (3) hemodynamic instability, (4) inability to correct dyspnea, and (5) $\mathrm{P}_{\mathrm{aO}} / \mathrm{F}_{\mathrm{IO}_{2}}$ $<100 \mathrm{~mm} \mathrm{Hg}$. Minor criteria were (1) breathing frequency $>35$ breaths/min, (2) blood $\mathrm{pH}<7.30$, (3) persistent tachypnea, (4) persistent activation of accessory respiratory muscles, and (5) $\mathrm{P}_{\mathrm{aO}_{2}} / \mathrm{F}_{\mathrm{IO}_{2}}<200 \mathrm{~mm} \mathrm{Hg}$.

Outcomes, including duration of NIV, duration of ICU stay, and duration of hospital stay, were collected when subjects were discharged or died. For subjects who underwent intubation, the duration of invasive mechanical ventilation was also recorded.

Data were analyzed using SPSS 17.0 (SPSS, Chicago, Illinois). Normally distributed continuous variables were analyzed with the unpaired Student $t$ test. Abnormally distributed continuous variables were analyzed with the MannWhitney $U$ test. Categorical variables were analyzed with the chi-square test or Fisher exact test when appropriate. Variables with a $P$ value of $<.2$ in univariate analysis and other variables clinically considered to be associated with NIV intolerance were entered into a multivariate logistic regression analysis. ${ }^{18}$ However, the pressure of the ventilator was not included in the multivariate logistic regression analysis; because we believed NIV intolerance would result in low pressures that subjects could tolerate. At the start of NIV, age, sex, diagnosis, APACHE II score, heart rate, breathing frequency, $\mathrm{pH}, \mathrm{P}_{\mathrm{aCO}}$, and $\mathrm{P}_{\mathrm{aO}_{2}} / \mathrm{F}_{\mathrm{IO}_{2}}$ were analyzed with stepwise multiple logistic regression analysis. Data collected after 1-2 h of NIV, including ventilator mode, mean arterial pressure, heart rate, breathing frequency, $\mathrm{pH}, \mathrm{P}_{\mathrm{aCO}}$, and $\mathrm{P}_{\mathrm{aO}} / \mathrm{F}_{\mathrm{IO}_{2}}$, were also analyzed
Table 2. Independent Risk Factors for Noninvasive Ventilation Intolerance Identified by Multivariate Logistic Regression Analysis

\begin{tabular}{lcc}
\hline \hline \multicolumn{1}{c}{ Risk Factors } & OR $(95 \% \mathrm{CI})$ & $P$ \\
\hline $\begin{array}{l}\text { Data collected at NIV initiation } \\
\text { Age, per y }\end{array}$ & $0.979(0.963-0.996)$ & .02 \\
$\quad$ Heart rate, beats $/ \mathrm{min}$ & $1.018(1.006-1.030)$ & .002 \\
Data collected at $1-2 \mathrm{~h}$ initiation of NIV* & $1.030(1.016-1.044)$ & $<.001$ \\
$\quad$ Heart rate, beats $/$ min & $1.062(1.027-1.099)$ & $<.001$ \\
$\quad$ Breathing frequency, breaths/min & & \\
& & \\
$*$ In the intolerant group, these data were collected at termination of NIV in 4 subjects who \\
received $<1$ h of NIV. \\
OR $=$ odds ratio \\
NIV $=$ noninvasive ventilation
\end{tabular}

with stepwise multiple logistic regression analysis. $P<.05$ was considered significant.

\section{Results}

A total of 961 subjects were enrolled in the study. Of these, 50 subjects $(5.2 \%)$ experienced NIV intolerance. NIV intolerance occurred a median of $2.4 \mathrm{~h}$ after the initiation of NIV (Fig. 1). Of 257 subjects who required intubation, 22 (8.6\%) subjects had experienced NIV intolerance. Table 1 and Figure 2 compare the data for subjects with and without NIV intolerance.

Independent risk factors of NIV intolerance were identified by multivariate logistic regression analysis (Table 2). At baseline, age was a protective factor for NIV intolerance; however, heart rate was a risk factor for NIV intolerance. After 1-2 h of NIV, independent risk factors for NIV intolerance were heart rate and breathing frequency.

Figure 3 shows the reasons intolerant subjects refused to receive NIV. Table 3 summarizes the outcomes for sub- 


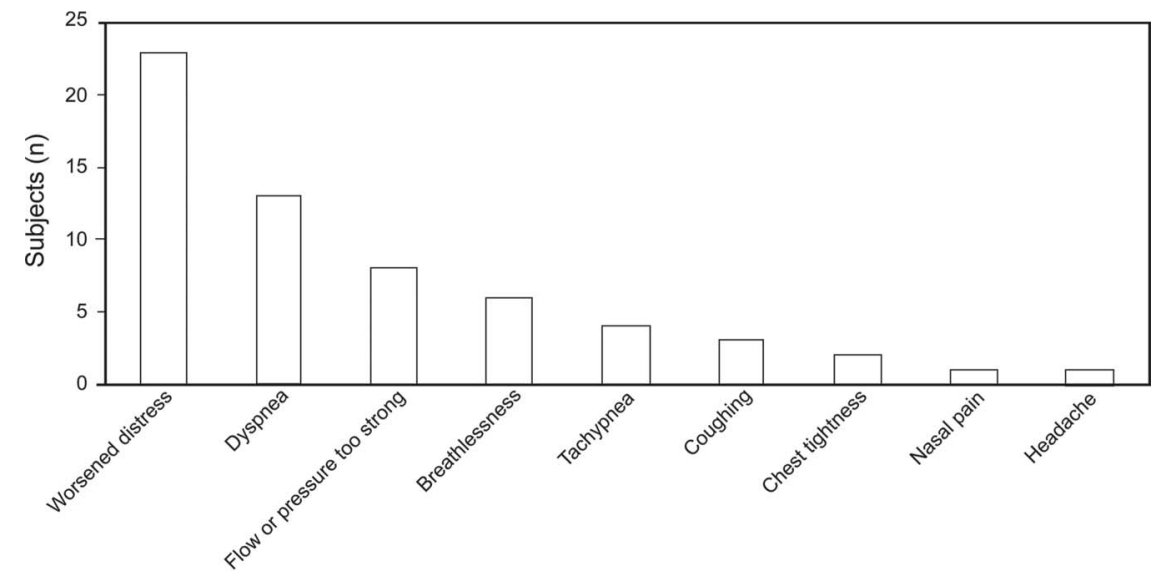

Fig. 3. Reasons given by subjects for refusing noninvasive ventilation, recorded at its termination.

Table 3. Outcomes for Subjects With and Without Noninvasive Ventilation Intolerance

\begin{tabular}{lccl}
\hline \hline \multicolumn{1}{c}{ Outcome } & $\begin{array}{c}\text { NIV Intolerance } \\
(n=50[5.2 \%])\end{array}$ & $\begin{array}{c}\text { NIV Tolerance } \\
(n=911[94.8 \%])\end{array}$ & $P$ \\
\hline ICU stay, median (IQR)d & $5.9(2.6-10.1)$ & $6.8(3.9-11.9)$ & .24 \\
Hospital stay, median (IQR) d & $12.8(6.8-18.0)$ & $14.6(8.5-24.0)$ & .10 \\
Intubation, $n$ (\%) & $22(44.0)$ & $235(25.8)$ & .008 \\
Mortality, $n$ (\%) & $17(34.0)$ & $204(22.4)$ & .08 \\
& & & \\
NIV = noninvasive ventilation & & & \\
IQR = interquartile range & & & \\
\hline
\end{tabular}

jects with and without NIV intolerance. Intolerant subjects had a higher intubation rate $(44.0 \%$ vs $25.8 \%, P=.008)$ and a trend toward higher mortality $(34.0 \%$ vs $22.4 \%$, $P=.08)$. Subgroup analysis was performed on subjects who underwent intubation (Table 4). Time from initiation of NIV to intubation was much shorter in NIV-intolerant subjects than in tolerant subjects $(2.4 \mathrm{~h}$ vs $60 \mathrm{~h}, P<.001)$.

\section{Discussion}

Here we report the rate of NIV intolerance in a relatively large sample of subjects. We found that age, heart rate, breathing frequency, and $\mathrm{P}_{\mathrm{aCO}_{2}}$ collected before NIV began and mean arterial pressure, heart rate, breathing frequency, and $\mathrm{P}_{\mathrm{aCO}}$ collected after 1-2 h of NIV were associated with NIV failure. Moreover, age and heart rate collected before NIV began and heart rate and breathing frequency collected after 1-2 h of NIV were independent risk factors for NIV intolerance. NIV intolerance in turn was associated with intubation and mortality. In addition, time from the initiation of NIV to intubation was much shorter in NIV-intolerant subjects than in tolerant subjects.

Previous studies have reported NIV intolerance rates of $11.4-15 \%$ in subjects who used an oronasal mask. ${ }^{16,17}$ These studies have strictly defined NIV intolerance as the subject's refusal to continue NIV because of discomfort caused by the mask. However, the sample size was small in the 2 studies ( 35 and 59 subjects, respectively). This may have led to inaccuracy in the reported rates of NIV intolerance. In our study, we enrolled 961 subjects. Our rate of NIV intolerance may be more accurate than others. However, we administered NIV to some subjects with mild acute respiratory failure. The subjects in our study may have had less severe respiratory failure than those in previous studies. This may be a reason for the relatively low rate of NIV intolerance in the present study.

At the initiation of NIV, intolerant subjects had a higher heart rate and breathing frequency than tolerant subjects. This may indicate that the condition of the intolerant subjects was more serious than that of the tolerant subjects, although APACHE II scores were not significantly different in the 2 groups. After 1-2 h of NIV, the vital signs and arterial blood gas results of the tolerant subjects had significantly improved. However, these variables did not improve in the intolerant subjects, except for $\mathrm{P}_{\mathrm{aO}_{2}} / \mathrm{F}_{\mathrm{IO}_{2}}$ (Fig. 2). In addition, the time from initiation of NIV to intubation was a median $2.4 \mathrm{~h}$ in the intolerant subjects, much shorter than in the tolerant subjects. NIV intolerance probably worsened the subjects' condition or at least did not improve it. Consequently, intubation was performed earlier in intolerant subjects.

NIV intolerance is common in patients with acute respiratory failure. However, few studies have reported why subjects cannot tolerate this device. In our study, we asked intolerant subjects why they refused NIV. The reasons varied, but 3 complaints were frequently heard: NIV worsened subjects' distress (46\%), NIV resulted in dyspnea (26\%), and the flow or pressure of NIV was too strong to bear $(16 \%)$. These factors can be due to patient-ventilator asynchrony. ${ }^{19}$ However, some factors, such as NIV giving subjects a continuous cough or headache, cannot be ex- 
Table 4. Comparison of Data for Subjects With and Without Noninvasive Ventilation Intolerance Who Underwent Intubation

\begin{tabular}{|c|c|c|c|}
\hline Factors & NIV Intolerance $(n=22)$ & NIV Tolerance $(n=235)$ & $P$ \\
\hline Age, mean \pm SD y & $56.3 \pm 23.5$ & $69.6 \pm 13.6$ & $<.001$ \\
\hline Male/female, $n$ & $14 / 8$ & $178 / 57$ & .21 \\
\hline \multicolumn{4}{|l|}{ Diagnosis } \\
\hline COPD exacerbation, $n(\%)$ & $8(36.4)$ & $101(43)$ & .65 \\
\hline Pneumonia, $n(\%)$ & $11(50)$ & $78(33.2)$ & .16 \\
\hline ARDS, $n(\%)$ & $2(9.1)$ & $21(8.9)$ & $>.99$ \\
\hline Asthma, $n(\%)$ & $0(0)$ & $7(3)$ & $>.99$ \\
\hline Pulmonary cancer, $n(\%)$ & $1(4.5)$ & $9(3.8)$ & .60 \\
\hline Pulmonary embolism, $n(\%)$ & $0(0)$ & $3(1.3)$ & $>.99$ \\
\hline Other, $n(\%)$ & $0(0)$ & $16(6.8)$ & .38 \\
\hline GCS, mean $\pm \mathrm{SD}$ & $14.5 \pm 1.3$ & $14.3 \pm 1.8$ & .75 \\
\hline $\mathrm{GCS}=15, n(\%)$ & $17(77)$ & $181(77)$ & $>.99$ \\
\hline $\mathrm{GCS}=14, n(\%)$ & $2(9)$ & $30(13)$ & $>.99$ \\
\hline $\mathrm{GCS} \leq 13, n(\%)$ & $3(14)$ & $24(10)$ & .71 \\
\hline \multicolumn{4}{|l|}{ Data collected at NIV initiation } \\
\hline APACHE II score, mean \pm SD & $20.5 \pm 6.9$ & $20.0 \pm 5.7$ & .68 \\
\hline Mean arterial pressure, mean $\pm \mathrm{SD} \mathrm{mm} \mathrm{Hg}$ & $99 \pm 23$ & $98 \pm 19$ & .87 \\
\hline Heart rate, mean $\pm \mathrm{SD}$ beats $/ \mathrm{min}$ & $137 \pm 29$ & $121 \pm 24$ & .004 \\
\hline Respiratory rate, mean $\pm \mathrm{SD}$ breaths/min & $35 \pm 8$ & $32 \pm 7$ & .11 \\
\hline $\mathrm{pH}$, mean $\pm \mathrm{SD}$ & $7.30 \pm 0.20$ & $7.37 \pm 0.12$ & .02 \\
\hline $\mathrm{P}_{\mathrm{aCO}_{2}}$, mean $\pm \mathrm{SD} \mathrm{mm} \mathrm{Hg}$ & $46 \pm 27$ & $51 \pm 25$ & .39 \\
\hline $\mathrm{P}_{\mathrm{aO}_{2}} / \mathrm{F}_{\mathrm{IO}_{2}}$, mean $\pm \mathrm{SD} \mathrm{mm} \mathrm{Hg}$ & $157 \pm 82$ & $153 \pm 82$ & .80 \\
\hline \multicolumn{4}{|l|}{ Data collected at $1-2 \mathrm{~h}$ after initiation of NIV, mean $\pm \mathrm{SD}^{*}$} \\
\hline IPAP, $\mathrm{cm} \mathrm{H}_{2} \mathrm{O}$ & $11 \pm 4$ & $15 \pm 4$ & $<.001$ \\
\hline $\mathrm{EPAP}, \mathrm{cm} \mathrm{H}_{2} \mathrm{O}$ & $4 \pm 1$ & $5 \pm 2$ & .001 \\
\hline Mean artery pressure, $\mathrm{mm} \mathrm{Hg}$ & $102 \pm 23$ & $93 \pm 16$ & .01 \\
\hline Heart rate, beats/min & $143 \pm 24$ & $113 \pm 23$ & $<.001$ \\
\hline Breathing frequency, breaths/min & $39 \pm 13$ & $29 \pm 9$ & $<.001$ \\
\hline $\mathrm{pH}$ & $7.34 \pm 0.13$ & $7.38 \pm 0.12$ & .21 \\
\hline $\mathrm{P}_{\mathrm{aCO}_{2}}, \mathrm{~mm} \mathrm{Hg}$ & $46 \pm 25$ & $52 \pm 26$ & .36 \\
\hline $\mathrm{P}_{\mathrm{aO}_{2}} / \mathrm{F}_{\mathrm{IO}_{2}}, \mathrm{~mm} \mathrm{Hg}$ & $180 \pm 107$ & $158 \pm 83$ & .26 \\
\hline Time from NIV initiation to intubation, median (IQR) h & $2.4(1.9-3.0)$ & $60(17-144)$ & $<.001$ \\
\hline Duration of invasive mechanical ventilation, median (IQR) d & $5.2(0.7-10.1)$ & $5.0(2.4-7.7)$ & .76 \\
\hline ICU stay, median (IQR) d & $8.9(1.2-13.4)$ & $9.0(4.6-15.6)$ & .17 \\
\hline Hospital stay, median (IQR) d & $10.1(6.1-15.7)$ & $14.7(6.5-24.2)$ & .25 \\
\hline Mortality, $n(\%)$ & 14 (63.6) & $150(63.8)$ & $>.99$ \\
\hline $\begin{array}{l}\text { Normally distributed data are reported as mean } \pm \mathrm{SD} \text {, and non-normally distribut } \\
{ }^{*} \text { In the intolerant group, these data were collected at termination of NIV in } 2 \text { sub } \\
\text { NIV = noninvasive ventilation } \\
\text { GCS = Glasgow coma score } \\
\text { APACHE II = Acute Physiology and Chronic Health Evaluation II } \\
\text { IPAP = inspiratory positive airway pressure } \\
\text { EPAP = expiratory positive airway pressure } \\
\text { IQR = interquartile range }\end{array}$ & $\begin{array}{l}\text { reported as median and interquartile } \\
\text { eceived }<1 \mathrm{~h} \text { of NIV. }\end{array}$ & & \\
\hline
\end{tabular}

plained by patient-ventilator asynchrony. This may be an interesting issue for further exploration.

Previous studies have reported several methods for dealing with NIV intolerance. Antonelli et $\mathrm{al}^{20}$ reported that subjects who used a facial mask had a higher proportion of NIV failure resulting from NIV intolerance than those who used a helmet. Roy et $\mathrm{al}^{21}$ reported that vital signs and arterial blood gas tests improved in subjects who could not tolerate a nasal mask or oronasal mask and switched to a full face mask. This indicates that changing the interface may improve NIV tolerance in some subjects. In addition, Rocco et $\mathrm{al}^{22}$ reported that analgesia and sedation improved tolerance in subjects who could not tolerate a helmet or total face mask. Although analgesia and sedation may improve NIV tolerance, they should only be used by trained ICU physicians and with selected patients.

Another interesting finding in our study is that not all NIV-intolerant subjects required intubation because we en- 
rolled some subjects with mild respiratory failure. The therapeutic effect of NIV on managing respiratory failure was between those of oxygen therapy and invasive mechanical ventilation. There are large areas of overlap between oxygen therapy and invasive mechanical ventilation. In subjects with mild respiratory failure, the intubation rate was very low. However, 2 previous studies reported that subjects with mild respiratory failure received benefits from NIV. ${ }^{23,24}$ Thus, the use of NIV in patients with mild respiratory failure is reasonable but perhaps unnecessary.

Our study has several limitations. First, our hospital only used oronasal masks for NIV; thus, these results reflect NIV intolerance in subjects using an oronasal mask only. However, the oronasal mask is the most common interface for NIV. In Europe and India, nearly $70 \%$ of physicians use oronasal masks. ${ }^{25,26}$ In the United States, $76 \%$ of emergency physicians reported using oronasal masks in $>50 \%$ of cases, and in $17 \%$ of centers, only oronasal masks were used. ${ }^{27}$ Thus, our study reflects most cases of NIV intolerance. Second, NIV was initiated in some subjects with mild acute respiratory failure. Perhaps some subjects did not really need NIV. Third, air leaks around the oronasal mask may play an important role in NIV intolerance. We did not record air leaks, although we kept them at $<30 \mathrm{~L} / \mathrm{min}$. Fourth, organ dysfunction may influence NIV intolerance, but this information was lacking. The results may be skewed because of these limitations.

\section{Conclusion}

This study shows a rate of NIV intolerance of $5.2 \%$ in subjects using an oronasal mask. Younger subjects with a high heart rate and breathing frequency were more likely to experience NIV intolerance. They showed no improvement in mean arterial pressure, heart rate, or breathing frequency after 1-2 $\mathrm{h}$ of NIV. Moreover, they were more likely to experience intubation and to experience it earlier.

\section{REFERENCES}

1. Burns KE, Meade MO, Premji A, Adhikari NK. Noninvasive ventilation as a weaning strategy for mechanical ventilation in adults with respiratory failure: a Cochrane systematic review. CMAJ 2014; 186(3):E112-E122.

2. Keenan SP, Sinuff T, Burns KE, Muscedere J, Kutsogiannis J, Mehta S, et al. Clinical practice guidelines for the use of noninvasive positivepressure ventilation and noninvasive continuous positive airway pressure in the acute care setting. CMAJ 2011;183(3):E195-E214.

3. Ram FS, Picot J, Lightowler J, Wedzicha JA. Non-invasive positive pressure ventilation for treatment of respiratory failure due to exacerbations of chronic obstructive pulmonary disease. Cochrane Database Syst Rev 2004;(1):CD004104.

4. Vital FM, Saconato H, Ladeira MT, Sen A, Hawkes CA, Soares B, et al. Non-invasive positive pressure ventilation (CPAP or bilevel NPPV) for cardiogenic pulmonary edema. Cochrane Database Syst Rev 2008;(3):CD005351.
5. Hess DR. Noninvasive ventilation for acute respiratory failure. Respir Care 2013;58(6):950-972.

6. Ozyilmaz E, Ugurlu AO, Nava S. Timing of noninvasive ventilation failure: causes, risk factors, and potential remedies. BMC Pulm Med $2014 ; 14: 19$

7. Antonelli M, Conti G, Esquinas A, Montini L, Maggiore SM, Bello $\mathrm{G}$, et al. A multiple-center survey on the use in clinical practice of noninvasive ventilation as a first-line intervention for acute respiratory distress syndrome. Crit Care Med 2007;35(1):18-25.

8. Carlucci A, Richard JC, Wysocki M, Lepage E, Brochard L, SRLF Collaborative Group on Mechanical Ventilation. Noninvasive versus conventional mechanical ventilation. An epidemiologic survey. Am J Respir Crit Care Med 2001;163(4):874-880.

9. Rocco M, Dell'Utri D, Morelli A, Spadetta G, Conti G, Antonelli M, Pietropaoli P. Noninvasive ventilation by helmet or face mask in immunocompromised patients: a case-control study. Chest 2004; 126(5):1508-1515.

10. Dohna-Schwake C, Stehling F, Tschiedel E, Wallot M, Mellies U. Non-invasive ventilation on a pediatric intensive care unit: feasibility, efficacy, and predictors of success. Pediatr Pulmonol 2011;46(11): 1114-1120.

11. Antro C, Merico F, Urbino R, Gai V. Non-invasive ventilation as a first-line treatment for acute respiratory failure: "real life" experience in the emergency department. Emerg Med J 2005;22(11):772777.

12. Antonelli M, Conti G, Moro ML, Esquinas A, Gonzalez-Diaz G, Confalonieri M, et al. Predictors of failure of noninvasive positive pressure ventilation in patients with acute hypoxemic respiratory failure: a multi-center study. Intensive Care Med 2001;27(11):17181728.

13. Fan L, Zhao Q, Liu Y, Zhou L, Duan J. Semiquantitative cough strength score and associated outcomes in noninvasive positive pressure ventilation patients with acute exacerbation of chronic obstructive pulmonary disease. Respir Med 2014;108(12): 1801-1807.

14. Plant PK, Owen JL, Elliott MW. Early use of non-invasive ventilation for acute exacerbations of chronic obstructive pulmonary disease on general respiratory wards: a multicentre randomised controlled trial. Lancet 2000;355(9219):1931-1935.

15. Antonelli M, Conti G, Rocco M, Bufi M, De Blasi RA, Vivino G, et al. A comparison of noninvasive positive-pressure ventilation and conventional mechanical ventilation in patients with acute respiratory failure. N Engl J Med 1998;339(7):429-435.

16. Kwok H, McCormack J, Cece R, Houtchens J, Hill NS. Controlled trial of oronasal versus nasal mask ventilation in the treatment of acute respiratory failure. Crit Care Med 2003;31(2):468-473.

17. Fernández-Vivas M, Caturla-Such J, González de la Rosa J, AcostaEscribano J, Alvarez-Sánchez B, Cánovas-Robles J. Noninvasive pressure support versus proportional assist ventilation in acute respiratory failure. Intensive Care Med 2003;29(7):1126-1133.

18. Hernán MA, Hernández-Díaz S, Werler MM, Mitchell AA. Causal knowledge as a prerequisite for confounding evaluation: an application to birth defects epidemiology. Am J Epidemiol 2002;155(2): 176-184.

19. Hess DR. Patient-ventilator interaction during noninvasive ventilation. Respir Care 2011;56(2):153-165; discussion 165-157.

20. Antonelli M, Conti G, Pelosi P, Gregoretti C, Pennisi MA, Costa R, et al. New treatment of acute hypoxemic respiratory failure: noninvasive pressure support ventilation delivered by helmet: a pilot controlled trial. Crit Care Med 2002;30(3):602-608.

21. Roy B, Cordova FC, Travaline JM, D’Alonzo GE Jr, Criner GJ. Full face mask for noninvasive positive-pressure ventilation in patients with acute respiratory failure. J Am Osteopath Assoc 2007;107(4): 148-156. 


\section{NIV INTOLERANCE}

22. Rocco M, Conti G, Alessandri E, Morelli A, Spadetta G, Laderchi A, et al. Rescue treatment for noninvasive ventilation failure due to interface intolerance with remifentanil analgosedation: a pilot study. Intensive Care Med 2010;36(12):2060-2065.

23. Collaborative Research Group of Noninvasive Mechanical Ventilation for Chronic Obstructive Pulmonary D. Early use of non-invasive positive pressure ventilation for acute exacerbations of chronic obstructive pulmonary disease: a multicentre randomized controlled trial. Chin Med J 2005;118(24):2034-2040.

24. Zhan Q, Sun B, Liang L, Yan X, Zhang L, Yang J, et al. Early use of noninvasive positive pressure ventilation for acute lung injury: a multicenter randomized controlled trial. Crit Care Med 2012;40(2): 455-460.

25. Crimi C, Noto A, Princi P, Esquinas A, Nava S. A European survey of noninvasive ventilation practices. Eur Respir J 2010;36(2):362369.

26. Chawla R, Sidhu US, Kumar V, Nagarkar S, Brochard L. Noninvasive ventilation: a survey of practice patterns of its use in India. Indian J Crit Care Med 2008;12(4):163-169.

27. Hess DR, Pang JM, Camargo CA Jr. A survey of the use of noninvasive ventilation in academic emergency departments in the United States. Respir Care 2009;54(10):1306-1312.

This article is approved for Continuing Respiratory Care Education credit. For information and to obtain your CRCE

(free to AARC members) visit

www.rcjournal.com 